\title{
FÓRUM SOBRE MEDICALIZAÇÃO DA EDUCAÇÃO E DA SOCIEDADE. Grupo de Trabalho Educação \& Saúde. Recomendações de práticas não medicalizantes para profissionais e serviços de saúde e educação. São Paulo, 2012 1 \\ Lygia Sousa Viegas Professora Adjunta da Faculdade de Educação da UFBA lyosviegas@gmail.com \\ (1) Disponível em <http:// medicalizacao.com.br/wp- content/uploads/2012/11/ RECOMENDACOES.pdf $>$. Acesso em: 24 de abril de 2013
}

\begin{abstract}
Resumo: A presente resenha apresenta os principais elementos constitutivos do documento intitulado Recomendações de práticas não medicalizantes para profissionais e serviços de saúde e educação, publicado pelo Grupo de Trabalho Educação \& Saúde, do Fórum sobre medicalização da educação e da sociedade. Tal resenha se justifica pelo pioneirismo e relevância do documento analisado. Para tanto, dá ênfase aos aspectos relativos às recomendações no campo da educação, apresentando sua fundamentação teórico-metodológica, bem como as principais sugestões apontadas no documento. Espera-se, a partir da resenha, contribuir com a divulgação desse importante trabalho de compilação realizado pelo grupo que o publicou.
\end{abstract}

Resenha

Mais do que esperada, a publicação de "Recomendações de práticas não medicalizantes para profissionais e serviços de saúde e educação", capitaneada pelo Fórum sobre medicalização da educação e da sociedade, foi mesmo comemorada por importantes setores da educação e da saúde, por representar um passo significativo no enfrentamento da patologização de crianças e adolescentes com dificuldades escolares.

$\mathrm{Na}$ introdução, os autores explicitam o que entendem por medicalização:

\begin{abstract}
o processo por meio do qual as questões da vida social complexas, multifatoriais e marcadas pela cultura e pelo tempo histórico - são reduzidas a um tipo de racionalidade que vincula artificialmente os desvios em relação às normas sociais a um suposto determinismo orgânico que se expressaria no adoecimento do indivíduo. (p. 14)
\end{abstract}

Citando exemplos de educação medicalizada, merece destaque a síndrome de burnout, que escamoteia as péssimas condições de 
(2) Compuseram o GT profissionais de antropologia fonoaudiologia, medicina, pedagogia e psicologia, das seguintes instituições: Associação Palavra Criativa/IFONO, Centro de Saúde Escola "Samuel Barnsley Pessoa" da Faculdade de Medicina da Universidade de São Paulo (USP), Departamento de Pediatria da Faculdade de Medicina da Universidade de Campinas (UNICAMP), Departamento de Psicologia Clínica da Faculdade de Psicologia da Universidade do Estado de São Paulo

(UNESP), Campus Assis, Grupo Interinstitucional Queixa Escolar Instituto SEDES Sapientiae, Laboratório Interinstitucional de Estudos e Pesquisa em Psicologia Escolar e Educacional, Rede Humaniza-SUS, Serviço de Psicologia do Hospital do Servidor Público Municipal e União de Mulheres do Município de São Paulo. trabalho a que professores estão submetidos; e a dislexia, suposta doença neurológica que impediria o aprendizado da língua escrita, explicação frágil nos termos da racionalidade médica, mas que cala o rico debate sobre a complexidade sócio-histórica envolvida nessa aprendizagem.

Ciente da importância desse debate, tal Fórum tem protagonizado a crítica à lógica medicalizante presente nas propostas hegemônicas de diagnóstico e tratamento daqueles que aprendem e se comportam de modos diferentes. Nesses debates, não é raro que, diante de casos emblemáticos, o Fórum seja interpelado por uma pergunta: "que fazer?". Essa questão, nada simples, reporta à dimensão teórico-metodológica; envolve estudo, debate, (auto) crítica, reconfiguração, experimentações, disposição para (re)pensar... Em uma palavra, envolve trabalho.

Para realizá-lo, foi montado o Grupo de Trabalho Educação \& Saúde, equipe interdisciplinar e multiprofissional ${ }^{2}$, que, durante aproximadamente um ano, reuniu-se sistematicamente, tendo por objetivo propor recomendações de como entender e atender tais situações sem recair no olhar medicalizante. Resultado de intenso trabalho, eis um documento riquíssimo, integralmente disponível no site do Fórum sobre Medicalização da Educação e da Sociedade, deixando clara a ausência de interesses corporativos.

Desde o início, chama atenção a linguagem ao mesmo tempo adequada e acessível, fundamentada na intencionalidade dos autores: que ele seja apropriado por profissionais que estão na ponta dos serviços de saúde e educação e que recebem crianças de quem se suspeita da capacidade de aprender e se comportar adequadamente.

Assim, dialogam diretamente com professores, médicos, psicólogos, assistentes sociais, fonoaudiólogos e enfermeiros, primeiro por meio de uma carta, e ao final, de uma despedida. Nesse diálogo, situam o aumento exponencial de encaminhamentos de alunos para serviços de saúde, situação reveladora da lógica medicalizante, pois parte da suposição de que as dificuldades vividas na escola decorrem de problemas dos alunos, mormente orgânicos. Decorrência desse reducionismo, a pessoa, "de aprendiz passa a ser entendida e acolhida como doente" (p. 5).

Contrapondo-se a essa visão, as Recomendações se pautam em ao menos duas viradas teórico-metodológicas: primeiro, a concepção de aprendizagem como processo multideterminado, 
atravessado por diversos fatores que desembocam nas condições sociais. Como decorrência óbvia, diante de uma criança que fracassa na escola, para além de aspectos individuais, outros devem ser considerados, com destaque para os históricos, políticos, econômicos, sociais, pedagógicos, institucionais e relacionais.

A segunda virada é a percepção de que a superação do olhar medicalizante implica em não focalizar apenas o que falta à criança (atenção, disciplina, alimento, coordenação motora), mas buscar suas potencialidades, ponto de partida para qualquer mudança significativa. E buscar potencialidades implica em se conectar com o sujeito singular, e não operar com a ultrageneralização que sustenta os manuais normativos.

Partindo dessa compreensão, os autores buscam afetar a atuação profissional em três âmbitos: ético-político (já que se apoiam numa tomada de posição e engajamento nas políticas públicas); acadêmico-científico (pois formulam estudos e argumentos teóricos sobre o tema) e técnico (uma vez que fornecem instrumentos potencializadores de práticas de educação e saúde).

Antes de elencar as recomendações propriamente ditas, deixam claro: este não é um manual fechado de diagnósticos e condutas. Ao contrário, trata-se de documento aberto, que partiTha um conjunto de experiências interessantes na educação e na saúde, a fim de potencializar escolas e serviços de saúde na criação de práticas não medicalizantes. Assim, apresentam capítulos diferentes para os seguintes campos ${ }^{3}$ : escolas; cuidados em saúde; fonoaudiólogos que trabalham com leitura e escrita; interação de profissionais em rede de serviços, setores e com a comunidade; e políticas públicas.

Ao adentrar no tema do fracasso escolar, os autores relatam uma curiosa situação vivenciada pelo GT: ao ouvir a opinião de educadores, foi notável que, se as escolas tendem a operar com a individualização, encaminhando alunos que aprendem ou se comportam de formas diferentes para os serviços de saúde; elas, ao mesmo tempo, reconhecem a importância de parceria respeitosa e democrática na direção de superar as dificuldades enfrentadas não apenas por alunos, mas também pelos educadores, todos cientes de que a escola oferecida está longe de ser a desejada. Ou seja, eles sabem que o número de alunos em sala de aula, a arquitetura da escola, as políticas educacionais, os materiais pedagógicos, o salário e as condições de trabalho afetam a aprendizagem e o
(3) No âmbito da presente resenha, serão destacados os aspectos relativos à educação, por ser este o foco da Revista Entreideias. No entanto, reconhecemos a riqueza e profundidade do material apresentado nas Recomendações no campo da saúde. 
comportamento dos alunos, o que significa reconhecer que os alunos não são o foco do problema. Dessa discussão, depreende-se que há nas escolas terreno propício à consolidação de práticas não patologizantes, que podem ser bem recebidas nas escolas também porque nelas há a aposta na potencialidade da escola em lidar com as dificuldades.

Analisando especificamente o capítulo "Recomendações para a escola como espaço potencial", destaca-se a crítica à busca de culpados, que focaliza apenas as faltas de todos, produzindo efeitos imobilizadores. E pergunta: "Não seria interessante mudar a lógica da culpa para a busca de possibilidades de compreensão dos envolvidos no processo ensino-aprendizagem e ampliar as intervenções e ações na escola?" (p. 43)

Sendo a escolarização um fenômeno complexo, a recomendação é a busca de estratégias que reconheçam essa complexidade. Rompendo a ideia de receita, apostam que casos singulares devem ser analisados em sua singularidade, que, ao mesmo tempo, deve ser compreendida no conjunto de aspectos envolvidos. As recomendações concretas são: implicar a escola como um todo na construção de projetos pedagógicos; discutir e refletir coletivamente sobre iniciativas e estratégias bem sucedidas; planejar estratégias grupais; articular os interesses de alunos e o de professores no planejamento das atividades pedagógicas; aprender e ensinar a conviver com a diferença.

Apesar de haver capítulos específicos para as diversas áreas envolvidas, há um capítulo que recomenda a parceria entre equipes, serviços e comunidade. Os autores sabem que tal proposta não é simples, sobretudo frente à sobrecarga de trabalho de todos; à dificuldade de trabalhar de forma partilhada; e por vezes à falta de autonomia dos profissionais e equipes. No entanto, o argumento em seu favor é consistente: acionar diferentes saberes e perspectivas caminha na superação da fragmentação das práticas dominantes. Entender tais dificuldades, em realidade, é parte do trabalho, e por isso há no documento sugestões de como lidar com elas.

Finalmente, vale enfatizar a importância do capítulo voltado para as políticas públicas, pensadas a partir da defesa de sua construção a partir da plena participação popular. Assim, recomendam a atuação junto aos conselhos de classe, sindicatos, instâncias de controle social, buscando abrir canais de comunicação com o poder público, bem como o amplo debate, esclarecendo a população 
sobre a complexidade envolvida nas políticas públicas de atenção às dificuldades de escolarização, sobretudo quando com contornos medializantes.

Vale ressaltar que, ao longo das Recomendações, os autores generosamente trazem diversas sugestões de leitura e vídeos para subsidiar a compreensão do tema, além de sugerirem algumas possíveis práticas. E deixam claro, tanto no começo, quanto no final, que se trata de um documento aberto, o que significa que ele é apenas um passo na direção da reunião de recomendações de práticas aos profissionais.

Mas esse não é um passo qualquer. É um passo fundamental, pois abre uma nova trilha, que agora pode ser percorrida e ampliada por outros profissionais, dando continuidade à consolidação de caminhos outros, que possam de fato acolher e enfrentar as dificuldades, mas apoiados no respeito às diferenças. Sem concebê-las como doenças.

Recebida: 25/04/2013. | Aceita: 24/07/2013. 